\title{
Adaptabilidade e estabilidade da produtividade de grãos de genótipos de caupi enramador de tegumento mulato(1)
}

\author{
Francisco Rodrigues Freire Filho(2), Valdenir Queiroz Ribeiro(2), \\ Maurisrael de Moura Rocha(2) e Ângela Celis de Almeida Lopes ${ }^{(3)}$
}

\begin{abstract}
Resumo - O objetivo deste trabalho foi avaliar a adaptabilidade e a estabilidade da produtividade de grãos de 16 genótipos de feijão caupi (Vigna unguiculata (L.) Walp.) utilizando o modelo de efeitos aditivos principais e interação multiplicativa. Os ensaios foram realizados em nove ambientes, locais e anos, da região Meio-Norte do Brasil, Estados do Piauí (PI) e Maranhão (MA), no período de 1999 a 2001. Os efeitos de ambientes e interação genótipos $\mathrm{x}$ ambientes, e os dois primeiros eixos da análise de componentes principais da interação foram significativos $(\mathrm{P}<0,01)$. A análise de componentes principais explicou $61,25 \%$ da soma de quadrados da interação genótipos x ambientes. Os genótipos TE93-244-23F e TE93-213-12F-1 reuniram genes para adaptabilidade e estabilidade, os quais podem ser cultivados em todos os ambientes. Os genótipos BR 17-Gurguéia, Canapuzinho e EPACE-10 apresentaram as maiores médias de produtividade, mas foram instáveis e com adaptação específica a ambientes de alta qualidade. Os ambientes mais favoráveis para a produtividade de grãos foram Bom Jesus, PI, 2000; Palmeira do Piauí, PI, 2001 e Sambaíba, MA, 2000. Não houve tendência de agrupamento de locais por Estado e a distribuição foi equilibrada em termos de qualidade ambiental.
\end{abstract}

Termos para indexação: Vigna unguiculata, interação genótipo-ambiente, previsibilidade.

\section{Adaptability and stability of grain yield in climbing and brown coat cowpea genotypes}

Abstract - The objective of this work was to evaluate the adaptability and the grain yield stability of 16 cowpea (Vigna unguiculata (L.) Walp.) genotypes using the additive main effects and multiplicative interaction model. The trials were carried out at nine environments, locations and years, of the MiddleNorth region of Brazil, states of Piauí (PI) and Maranhão (MA), in the period from 1999 to 2001. Environments and genotype $\mathrm{x}$ environment interaction effects, and the first two axes of the analysis of principal component of the interaction were significant $(\mathrm{P}<0.01)$. The analysis of principal components explained $61.25 \%$ of the sum of squares of the genotype $\mathrm{x}$ environment interaction. TE93-244-23F and TE93-210-12F-1 genotypes gathered genes for adaptability and stability, and can be cultivated in all environments. BR 17-Gurguéia, Canapuzinho and EPACE-10 genotypes presented the highest yield averages, but were unstable and with specific adaptation to environments of high quality. The environments more favorable were Bom Jesus, PI, 2000; Palmeira do Piauí, PI, 2001, and Sambaíba, MA, 2000. There was no tendency of locations grouping by State and the distribution was balanced in terms of environmental quality.

Index terms: Vigna unguiculata, genotype environment interaction, predictability.

\footnotetext{
(1) Aceito para publicação em 12 de março de 2003.

(2) Embrapa-Centro de Pesquisa Agropecuária do Meio-Norte, Caixa Postal 01, CEP 64006-220 Teresina, PI. E-mail freire@cpamn.embrapa.br, valdenir@cpamn.embrapa.br, mmrocha@cpamn.embrapa.br

(3) Universidade Federal do Piauí, Dep. de Biologia, Centro de Ciências da Natureza, Campus Ministro Petrônio Portela, Bloco 2, FG 1, Ininga, CEP 64049-550 Teresina, PI. E-mail: acalopes@bol.com.br
}

\section{Introdução}

A estabilidade e a adaptabilidade de genótipos são características importantes que devem receber muita atenção nos programas de melhoramento. A adaptabilidade refere-se à capacidade de os genótipos aproveitarem vantajosamente o estímulo do ambiente e a estabilidade diz respeito à capacida- 
de de os genótipos mostrarem comportamento altamente previsível em razão do estímulo do ambiente (Cruz \& Regazzi, 1994).

A estabilidade e a adaptabilidade, em feijão caupi, têm sido estudadas em vários trabalhos, com a predominância do uso de metodologias que utilizam regressão linear (Finlay \& Wilkinson, 1963; Eberhart \& Russel, 1966). Esses estudos têm subsidiado o melhoramento e o lançamento de cultivares em vários estados do Nordeste (Fernandes et al., 1990, 1993; Miranda et al., 1992, 1997; Santos et al., 2000; Freire Filho et al., 2001, 2002).

A regressão linear, entretanto, por ser um modelo aditivo, pode não descrever satisfatoriamente o comportamento dos genótipos nos ambientes (Yau, 1995) e depende do grau de influência dos efeitos ambientais sobre os genótipos (Rocha, 2002). Ela explica muito pouco da heterogeneidade da regressão e pode falhar nos casos em que ocorre grande diversidade ambiental (Crossa, 1990). Diante dessas limitações, modelos alternativos de análises têm sido buscados, no sentido de explicar melhor a interação genótipos $\mathrm{x}$ ambientes (GxE). Atualmente, vem aumentando o uso do modelo de efeitos aditivos principais e interação multiplicativa (AMMI), que combina a análise de variância dos efeitos aditivos principais de genótipos e ambientes com a análise de componentes principais do efeito multiplicativo da interação GxE (Zobel et al., 1988; Duarte \& Vencovsky, 1999).

Resultados preliminares confirmam a hipótese de que o primeiro componente principal da interação (CPI1) é superior à análise de regressão linear em explicar a interação GxE. A análise também é eficiente em recuperar o padrão (variação diretamente relacionada ao fenômeno da interação GxE e de interesse agronômico) e descartar o ruído (variação aleatória não relacionada ao fenômeno da interação $\mathrm{GxE}$, resultante, principalmente, de efeitos microambientais) presente na variação total, contida dentro da soma de quadrados da interação $\mathrm{GxE}\left(\mathrm{SQ}_{\mathrm{GxE}}\right)$. Por esta abordagem, somente o padrão é incluído no modelo, por reter apenas os CPI significativos em seu termo multiplicativo (Zobel et al., 1988; Annicchiarico, 1997).

O número ótimo de CPI a ser retido no modelo AMMI ou o melhor modelo da família AMMI
(AMMI0, AMMI1, AMMI2, ..., AMMIn) pode ser determinado por duas abordagens: preditiva e posdictive (Fox et al., 1997).

$\mathrm{Na}$ abordagem preditiva, a técnica mais usada é a validação cruzada. Nela, os dados originais de repetições são divididos em dois grupos: dados de modelagem (dados de uma repetição) e os dados de validação (dados das demais repetições); os dois grupos são analisados, paralelamente, várias vezes, para cada modelo da família AMMI por reamostragem aleatória dos dados de repetições, que são então comparados tomando-se por base a diferença preditiva média (DPM). O modelo mais preditivo e parcimonioso é aquele com menor DPM (Gauch, 1992; Gauch \& Zobel, 1996).

$\mathrm{Na}$ abordagem posdictive utiliza-se de teste de hipótese para avaliar as significâncias dos CPI ou seus resíduos (resíduo AMMI). O teste F de Gollob (1968) é o mais adotado, por ser de fácil análise. No entanto, outros testes $\left(\mathrm{F}_{\mathrm{GH} 2}\right.$ e $\left.\mathrm{F}_{\mathrm{R}}\right)$ têm sido sugeridos na literatura e indicados como sendo mais robustos (Piepho, 1995).

Alguns estudos têm sido feitos comparando o modelo AMMI com a regressão linear e a conclusão predominante é que o primeiro tem sido mais eficiente em explicar a interação GxE (Yau, 1995; Annicchiarico, 1997; Pereira \& Costa, 1998; Acciaresi \& Chidichimo, 1999; Rocha, 2002). No caso do feijão caupi, não há relatos na literatura do uso do modelo AMMI em estudos de adaptabilidade e estabilidade fenotípica.

O objetivo deste trabalho foi avaliar a adaptabilidade e a estabilidade da produção de grãos de 16 genótipos de feijão caupi utilizando o modelo AMMI.

\section{Material e Métodos}

Foram utilizados dados de produtividade de grãos de caupi de porte enramador e de tegumento mulato dos ensaios estaduais do programa de melhoramento de feijão caupi da Embrapa-Centro de Pesquisa Agropecuária do Meio-Norte, realizados de 1999 a 2001, nos estados do Piauí (PI) e do Maranhão (MA). Os tratamentos consistiram de 16 genótipos (11 linhagens, três cultivares locais e duas cultivares melhoradas): TE90-180-88E(TE86-75-57E X TEx1-69E), TE93-200-49F (TE86-75-37E-1 X TE89-1501G), TE93-213-12F-1 (CNCx252-1E/FV X TEx4-38E), 
TE93-213-12F-2 (CNCx252-1E/FV X TEx4-38E), TE93-214-11F (TEx4-38E X CNCx252-1E/FV), TE93-244-23F (IPA 206 X TE86-733G), TE94-256-6E (IT89-KD295-1 X IT86D-716), TE94-268-3E (TE87-108-6G X EPACE-10), TE94-269-1E (TE87-108-6G X BR 14-Mulato), TE94-270-4E (TE89-162-14G XEPACE-10), IPA-206 (371 X CNCx11-2E), Paulista (Ceará), CanapuRV-1 (Rio Grande do Norte), Canapuzinho (Piauí), EPACE-10 (Seridó X Tvu 1888) e BR 17-Gurguéia (BR 10-Piauí X CE-315). A cultivar BR 17-Gurguéia foi utilizada como testemunha.

Os ambientes de avaliação consistiram da combinação de local e ano, o que resultou em nove ambientes: Baixa Grande do Ribeiro, PI, 2000: BG00; Brejo, MA, 2001: BR01; Barra do Corda, MA, 2001: BC01; Bom Jesus, PI, 2000: BJ00; Castelo do Piauí, PI, 1999: CP99; Castelo do Piauí, PI, 2000: CP00; Palmeira do Piauí, PI, 2001: PA01; Sambaíba, MA, 2000: SA00; Teresina, PI, 2000: TE00).

Todos os ensaios foram realizados no período de sequeiro (verão), considerado a época das chuvas na região Meio-Norte. O plantio ocorreu entre a última semana do mês de janeiro (Piauí) e a primeira de fevereiro (Maranhão), de forma que a colheita ocorresse sempre no final das chuvas. A adubação foi realizada atendendo às recomendações para os solos de cada local, geralmente com a aplicação de 40 a $80 \mathrm{~kg} \mathrm{ha}^{-1}$ de $\mathrm{P}_{2} \mathrm{O}_{5}$ e de 20 a $40 \mathrm{~kg} \mathrm{ha}^{-1} \mathrm{de}_{2} \mathrm{O}$. O uso de adubos nitrogenados não foi muito freqüente, tendo em vista que o feijão caupi é uma leguminosa que se beneficia da associação simbiótica com bactérias do gênero Rhizobium. Os tratos culturais consistiram do uso de herbicida e capina complementar para o controle de ervas daninhas. Foi aplicado inseticida para controle de insetos mastigadores (vaquinhas e lagartas) e sugadores (pulgões, percevejos e tripes), quando necessário.

Em todos os ensaios, utilizou-se o delineamento experimental de blocos casualizados, com quatro repetições. A parcela compreendeu quatro fileiras, e a área útil foi representada pelas duas fileiras centrais. Em alguns ensaios as parcelas tiveram as dimensões de $2 \times 5 \mathrm{~m}$ e em outros de $3 \times 5 \mathrm{~m}$, de acordo com o espaçamento entre fileiras, que foram de 0,50 e $0,75 \mathrm{~m}$, respectivamente. Em ambas as parcelas, o espaçamento entre plantas dentro da fileira foi de $0,25 \mathrm{~m}$. Os dados foram padronizados para uma mesma unidade de área.

A adaptabilidade e a estabilidade foram analisadas pelo modelo de efeitos aditivos principais e interação multiplicativa (AMMI), o qual representa um modelo linear e bilinear, compreendendo uma análise integrada em que os efeitos aditivos principais de genótipos e ambientes foram investigados pela análise de variância, e o efeito multiplicativo da interação genótipos x ambientes (GxE) foi decomposto pela análise de componentes principais (ACP). A análise foi realizada utilizando o programa SAS (SAS Institute, 1997), de acordo com o algoritmo sugerido por Duarte \& Vencovsky (1999). Esta considerou os efeitos de genótipos e ambientes como fixos. Foi adotado o modelo conforme a equação:

$\mathrm{Y}_{\mathrm{ij}}=\mu+\mathrm{g}_{\mathrm{i}}+\mathrm{e}_{\mathrm{j}}+\sum_{\mathrm{k}=1}^{\mathrm{n}} \lambda_{\mathrm{k}} \gamma_{\mathrm{ik}} \alpha_{\mathrm{jk}}+\rho_{\mathrm{ij}}+\varepsilon_{\mathrm{ij}}$,

em que: $Y_{i j}$ é a média do genótipo i no ambiente j; $\mu$ é a média geral; $g_{i}$ e $e_{j}$ são os efeitos do i-ésimo genótipo e j-ésimo ambiente, respectivamente; $\lambda_{\mathrm{k}}$ é o k-ésimo valor singular da matriz GxE; $\gamma_{\mathrm{ik}}$ e $\alpha_{\mathrm{jk}}$ são os k-ésimos valores singulares correspondentes ao i-ésimo genótipo e j-ésimo ambiente, respectivamente; $\rho_{\mathrm{ij}}$ é o resíduo da interação GxE; n é o número de eixos ou CPI retidos pelo modelo; e $\varepsilon_{\mathrm{ij}}$ é o erro experimental médio.

A seleção do modelo AMMI foi realizada segundo o critério posdictive, pelo teste $\mathrm{F}_{\mathrm{R}}$ apresentado por Piepho (1995), de acordo com a equação:

$\mathrm{F}_{\mathrm{R}, \mathrm{n}}=\left(\mathrm{SQ}_{\mathrm{GxE}}-\sum_{\mathrm{k}=1}^{\mathrm{n}} \lambda_{\mathrm{k}}^{2}\right) /\left(\mathrm{f}_{2} \cdot \mathrm{QM}_{\text {Erro médio }}\right)$,

com $\mathrm{f}_{2}=(\mathrm{g}-1-\mathrm{n})(\mathrm{e}-1-\mathrm{n})$, correspondendo ao número de graus de liberdade associados a cada parcela da interação GxE, definidos por Gollob (1968).

Este critério baseia-se na análise do ruído (resíduo de cada CPI ou eixo da interação, representando a variação aleatória não relacionada com o fenômeno da interação genótipos x ambientes), sendo selecionado aquele modelo da família AMMI que engloba pela primeira vez um eixo em que seu resíduo não seja significativo pelo teste $F_{R}$. Um modelo preditivo e parcimonioso é aquele que contempla poucos eixos, no máximo três; consumindo, assim, poucos graus de liberdade.

A interpretação da adaptabilidade e estabilidade dos genótipos e ambientes foi feita com base na análise gráfica em biplot. Segundo Duarte \& Vencovsky (1999), o termo biplot se refere a um tipo de gráfico contendo duas categorias de pontos ou marcadores; no caso, um referindo-se a genótipos e outro a ambientes.

\section{Resultados e Discussão}

A análise de variância mostrou que apenas os efeitos de ambientes e da interação GxE foram significativos $(\mathrm{P}<0,01)$ (Tabela 1). Esse resultado indica que os genótipos apresentaram comportamento diferenciado com os ambientes, o que justifica estudo mais aprofundado sobre o comportamento das linha- 
gens para identificar suas magnitudes de interação com os ambientes.

$\mathrm{Na}$ análise AMMI, a $\mathrm{SQ}_{\mathrm{GxE}}$ foi decomposta em oito CPIs; no entanto, somente os dois primeiros eixos (CPI1 e CPI2) foram significativos pelo teste $\mathrm{F}$ de Gollob (1968) e explicaram, respectivamente, $37,50 \%$ e $23,75 \%$, englobando um total de $61,25 \%$ da $\mathrm{SQ}_{\mathrm{GxE}}$ (Tabela 1). Para efeito de interpretação, são mostrados apenas os dois primeiros CPIs, já que o resíduo do CPI2 foi não significativo pelo teste $F_{R}$ (Piepho, 1995). Isto indica que o modelo mais preditivo é o AMMI2. Portanto, este foi selecionado para o estudo da estabilidade e adaptabilidade dos genótipos e ambientes.

No Brasil, ainda não há relatos na literatura do uso da análise AMMI em feijão caupi, e os resultados obtidos são em relação ao feijão comum (Borges et al., 2000), batata (Pereira \& Costa, 1998) e soja (Rocha, 2002). Nos dois primeiros trabalhos, o CPI1 explicou $43 \%$ e $44 \%$ da $\mathrm{SQ}_{\mathrm{GxE}}$, respectivamente; enquanto em soja, o CPI1 explicou de $23 \%$ a $39 \%$ da $\mathrm{SQ}_{\mathrm{GxE}}$.

Nos trabalhos citados, a variação explicada pelo $\mathrm{CPI} 1$, em relação à $\mathrm{SQ}_{\mathrm{GxE}}$ total, foi maior no caso de feijão e batata, e menor no caso da soja, quando comparada à obtida no presente trabalho. Nos resultados de Borges et al. (2000), o padrão foi distribuído em mais de dois eixos e os autores concluíram que a análise AMMI foi ineficiente para explicar a interação. Já nos resultados de Rocha (2002), a exemplo do que ocorreu no presente trabalho, a variação explicada pelos dois primeiros eixos foi baixa, mas a maioria desta foi padrão (poucos eixos significati- vos pelo teste $\mathrm{F}$ e muitos eixos - resíduo - não-significativos pelo teste $\mathrm{F}_{\mathrm{R}}$ )

A não-significância do resíduo indica que a variação contida nos demais eixos (CPI3 ao CPI8) é desprezível e contém apenas ruído (variação aleatória não relacionada com o fenômeno da interação), que pode diminuir a eficiência da interpretação da estabilidade dos genótipos e ambientes na análise gráfica. Assim, a interpretação gráfica, considerando apenas a variação contida nos dois primeiros eixos da ACP, é suficiente para avaliar a estabilidade dos genótipos e ambientes (Rocha, 2002).

A presença significativa de ruídos (variação não relacionada com a interação $\mathrm{GxE}$ ) dentro da $\mathrm{SQ}_{\mathrm{GxE}}$ pode ser atribuída à influência de fatores aleatórios (Nachit et al., 1992), mas também decorrente da grande variabilidade ambiental, o que contribui para diminuir o padrão adjacente à interação GxE nos primeiros eixos da ACP. Segundo Annicchiarico (1997), ambientes localizados em regiões tropicais são mais propensos à ocorrência de estresses ambientais.

No presente trabalho, a irregularidade pluviométrica, comum em todos os ambientes de avaliação, pode ter sido um dos principais fatores em termos de estresse ambiental. Isto pode determinar a ocorrência de ambientes contrastantes, gerar uma grande variação quanto a ambientes e contribuir para aumentar a variação não explicável (ruído) em detrimento da variação diretamente relacionada à interação GxE (padrão).

Após descartar a variação não relacionada com a interação, as médias dos genótipos e ambientes foram preditas com base na variação da interação $\mathrm{GxE}$

Tabela 1. Análise de efeitos aditivos principais e interação multiplicativa para o caráter produtividade de grãos $\left(\mathrm{kg} \mathrm{ha}^{-1}\right)$ de 16 genótipos de feijão caupi, avaliados em nove ambientes do Meio-Norte do Brasil.

\begin{tabular}{lrccc}
\hline Causas de variação & $\mathrm{GL}$ & $\mathrm{QM}$ & QSQ $_{\mathrm{GxE}} / \mathrm{CPI}^{(1)}$ & $\% \mathrm{SQ}_{\mathrm{GxE} \text { Acumulada }}$ \\
\hline Genótipos (G) & 15 & $24.224^{\mathrm{nS}}$ & - & - \\
Ambientes (E) & 8 & $4.048 .729^{* *}$ & - & - \\
GxE & 120 & $23.134^{* *}$ & - & - \\
CPI1 & 22 & $47.320^{* *}$ & 37,50 & 37,50 \\
Resíduo & & $17.705^{* *}$ & - & 62,50 \\
CPI2 & 98 & $32.966^{* *}$ & 23,75 & 61,25 \\
$\quad$ Resíduo & $13.791^{\mathrm{ns}}$ & - & 38,75 \\
Erro médio/r $^{(2)}$ & 78 & 11.438 & & - \\
\hline CV $(\%)$ & 404 & & &
\end{tabular}

(1)Porcentagem da soma de quadrados da interação genótipos x ambientes captada por CPI (Componente Principal da Interação). ${ }^{(2)}$ Número de repetições.

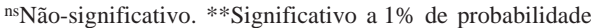


presente nos dois primeiros CPI ou com base no modelo AMMI2 (Tabela 2). Três genótipos apresentaram médias na faixa de 1.100 a $1.200 \mathrm{~kg} \mathrm{ha}^{-1}, 12 \mathrm{na}$ faixa de 1.000 a $1.100 \mathrm{~kg} \mathrm{ha}^{-1}$ e um na faixa de $900 \mathrm{a}$ $1.000 \mathrm{~kg} \mathrm{ha}^{-1}$. Em relação a ambientes, as médias preditas variaram de $163 \mathrm{~kg} \mathrm{ha}^{-1}$ em TE00 a $2.250 \mathrm{~kg} \mathrm{ha}^{-1}$ em SA00.

Os gráficos na forma de biplot (AMMI1 e AMMI2) foram utilizados para analisar a dispersão da variação dos genótipos e ambientes e da interação entre estes. O biplot AMMI1 contém a variação dos efeitos aditivos principais de genótipos e ambientes, visualizada na horizontal do gráfico (eixo das abcissas), e a variação dos efeitos multiplicativos da interação GxE, visualizada na vertical (eixo das ordenadas). No biplot AMMI2 são visualizados apenas os efeitos multiplicativos da interação GxE contidos nos dois primeiros CPI e dispersos em ambas as ordenadas do gráfico.

Quanto aos efeitos aditivos principais de genótipos e ambientes, observou-se pouca variação entre genótipos, que se agruparam em uma coluna em torno da média geral, relativamente aos efeitos de ambientes, que apresentaram alta variabilidade (Fi- gura 1). Isto sugere que estes interagiram fortemente com fatores macroambientais (locais, anos) ou microambientais (erros estocásticos ou aleatórios); consequentemente, o efeito multiplicativo da interação GxE, também foi bastante disperso.

O coeficiente de variância médio dos experimentos sugeriu bom padrão de precisão experimental na obtenção das médias de produtividade de grãos (Tabela 1), assim a baixa variabilidade do efeito de genótipos pode ter sido causada pelo parentesco existente entre estes, como, por exemplo, entre as linhagens TE93-200-49F, TE93-213-12F-1, TE93-21312F-2 e TE93-214-11F, e entre as linhagens TE94-2683E e TE94-270-4E. Outro fator que pode ter contribuído para a redução da variabilidade genética foi a forte pressão de seleção para aumentar o peso de 100 grãos e outros componentes de produtividade voltados para a qualidade, na fase de avaliação preliminar das linhagens. Baixa variabilidade de genótipos de feijão caupi também foi obtida por Freire Filho et al. (2002), em estudo sobre adaptabilidade e estabilidade fenotípica.

Para efeito de interpretação dos resultados quanto à adaptabilidade e estabilidade, no presente tra-

Tabela 2. Médias preditas para o caráter produtividade de grãos $\left(\mathrm{kg} \mathrm{ha}^{-1}\right)$ pelo modelo de efeitos aditivos principais e interação multiplicativa, considerando apenas os dois primeiros eixos da análise de componentes principais da interação (AMMI2) para 16 genótipos e nove ambientes do Meio-Norte do Brasil.

\begin{tabular}{|c|c|c|c|c|c|c|c|c|c|c|}
\hline \multirow[t]{2}{*}{ Genótipo } & \multicolumn{9}{|c|}{ Ambiente $^{(1)}$} & \multirow[t]{2}{*}{ Média } \\
\hline & TE00 & CP99 & CP00 & PA01 & BJ00 & BG00 & BR01 & $\mathrm{BC} 01$ & SA00 & \\
\hline TE93-200-49F & 439 & 559 & 1.010 & 1.528 & 1.261 & 1.007 & 748 & 909 & 2.107 & 1.063 \\
\hline TE93-213-2F-1 & 446 & 498 & 1.086 & 1.558 & 1.200 & 1.290 & 733 & 1.052 & 1.962 & 1.092 \\
\hline TE93-213-12F-2 & 369 & 413 & 1.014 & 1.455 & 1.103 & 1.224 & 634 & 963 & 1.851 & 1.003 \\
\hline TE93-214-11F & 494 & 531 & 1.133 & 1.438 & 1.158 & 1.277 & 661 & 967 & 1.876 & 1.059 \\
\hline TE93-244-23F & 438 & 503 & 1.064 & 1.540 & 1.203 & 1.225 & 725 & 1.013 & 1.980 & 1.077 \\
\hline TE94-256-6E & 439 & 554 & 1.002 & 1.391 & 1.196 & 927 & 654 & 786 & 2.016 & 996 \\
\hline TE94-268-3E & 394 & 452 & 1.027 & 1.481 & 1.144 & 1.200 & 667 & 967 & 1.909 & 1.027 \\
\hline TE94-269-1E & 426 & 584 & 966 & 1.559 & 1.310 & 883 & 785 & 875 & 2.210 & 1.066 \\
\hline TE94-270-4E & 440 & 517 & 1.050 & 1.501 & 1.201 & 1.151 & 707 & 955 & 1.989 & 1.057 \\
\hline TE90-180-88E & 472 & 553 & 1.069 & 1.419 & 1.188 & 1.090 & 665 & 874 & 1.962 & 1.033 \\
\hline Paulista & 163 & 289 & 773 & 1.709 & 1.189 & 1.038 & 778 & 1.059 & 2.108 & 1.012 \\
\hline CanapuRV-1 & 235 & 353 & 847 & 1.726 & 1.228 & 1.101 & 810 & 1.092 & 2.129 & 1.058 \\
\hline IPA-206 & 415 & 506 & 1.007 & 1.418 & 1.166 & 1.032 & 651 & 852 & 1.963 & 1.001 \\
\hline EPACE-10 & 298 & 423 & 910 & 1.860 & 1.330 & 1.188 & 924 & 1.211 & 2.250 & 1.155 \\
\hline Canapuzinho & 431 & 396 & 1.164 & 1.634 & 1.126 & 1.673 & 731 & 1.271 & 1.789 & 1.135 \\
\hline$\underline{B R}$ 17-Gurguéia $^{(2)}$ & 603 & 587 & 1.289 & 1.509 & 1.191 & 1.556 & 716 & 1.127 & 1.837 & 1.157 \\
\hline Média & 406 & 482 & 1.026 & 1.545 & 1.200 & 1.179 & 724 & 998 & 1.996 & \\
\hline
\end{tabular}

(1)BC01: Barra do Corda, MA, 2001; BG00: Baixa Grande do Ribeiro, PI, 2000; BJ00: Bom Jesus, PI, 2000; BR01: Brejo, MA, 2001; CP99: Castelo do Piauí, PI, 1999; CP00: Castelo do Piauí, PI, 2000; PA01: Palmeira do Piauí, PI, 2001; SA00: Sambaíba, MA, 2000; TE00: Teresina, PI, 2000. ${ }^{(2)}$ Testemunha. 
balho a expressão alta adaptabilidade será utilizada como sinônimo de alta produtividade, e a expressão ampla adaptabilidade, como sinônimo de alta estabilidade.

Os genótipos mais produtivos foram BR 17-Gurguéia, EPACE-10, Canapuzinho, TE93-213-12F-1, TE93-244-23F e TE94-269-1E, com produtividades acima da média geral $\left(1.062 \mathrm{~kg} \mathrm{ha}^{-1}\right)$ (Figura 1). Os genótipos mais estáveis foram TE93-244-23F, TE93-213-12F-1, TE94-268-3E e TE94-270-4E (Figuras 1 e 2). Estes podem ser cultivados em todos os locais onde foram feitos os estudos. Entre estes, apenas os genótipos TE93-213-12F-1 e TE93-244-23F apresentaram produtividades acima da média geral. Entre os dois grupos (produtivos e estáveis), apenas os genótipos TE93-213-12F-1 e TE93-244-23F foram comuns aos dois grupos, indicando que esses genótipos associaram adaptabilidade com estabilidade.

Os genótipos TE93-213-12F-1, TE93-213-12F-2, TE93-244-23F, TE94-268-3E e TE94-270-4E apresentaram similaridade em termos de interação associada à estabilidade, ao passo que os genótipos Paulista, CanapuRV-1 e EPACE-10 mostraram similaridade quanto à interação associada à instabilidade (Figura 1). Houve similaridades de interação entre os genótipos TE93-200-49F, TE94-256-6E e TE94-269-1E, e entre TE90-180-88E e IPA-206. Para estes genótipos, a similaridade em termos de interação não foi acompanhada de similaridade genética, já que não se observou parental comum em suas genealogias.

Os genótipos EPACE-10, Canapuzinho e BR 17-Gurguéia apresentaram as maiores médias, mas mostraram adaptabilidade específica a ambientes associados com altas médias, como Baixa Grande do Ribeiro, PI, 2000, e Palmeira do Piauí, PI, 2001 (Figuras 1 e 2). Santos et al. (2000) e Freire Filho et al. (2002), avaliando um grupo de genótipos de feijão caupi sob cultivo de sequeiro e utilizando o método de Eberhart \& Russel (1966), também identificaram alta adaptabilidade da cultivar BR 17-Gurguéia.

Os ambientes mais favoráveis foram Baixa Grande do Ribeiro, PI, 2000; Bom Jesus, PI, 2000; Sambaíba, MA, 2000, e Palmeira do Piauí, PI, 2001.

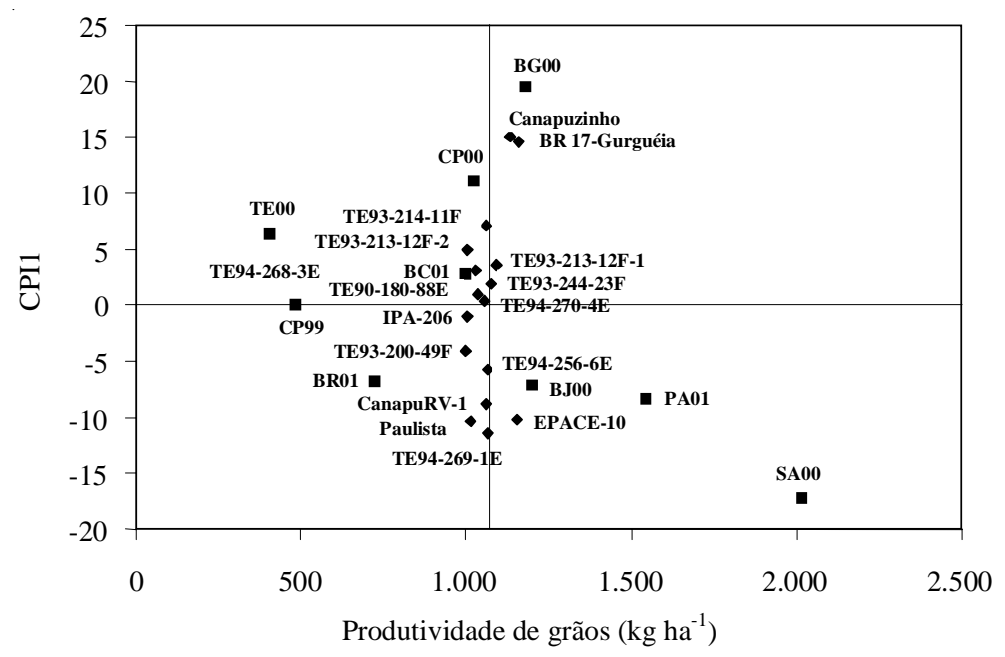

Figura 1. Biplot AMMI1 ou modelo de efeitos aditivos principais e interação multiplicativa, considerando apenas o primeiro eixo da análise de componentes principais da interação (CPI1) x produtividade de grãos, de 16 genótipos $(\bullet)$ de feijão caupi, avaliados em nove ambientes (ם) do Meio-Norte do Brasil (BC01: Barra do Corda, MA, 2001; BG00: Baixa Grande do Ribeiro, PI, 2000; BJ00: Bom Jesus, PI, 2000; BR01: Brejo, MA, 2001; CP99: Castelo do Piauí, PI, 1999; CP00: Castelo do Piaú, PI, 2000; PA01: Palmeira do Piauí, PI, 2001; SA00: Sambaíba, MA, 2000; TE00: Teresina, PI, 2000). 


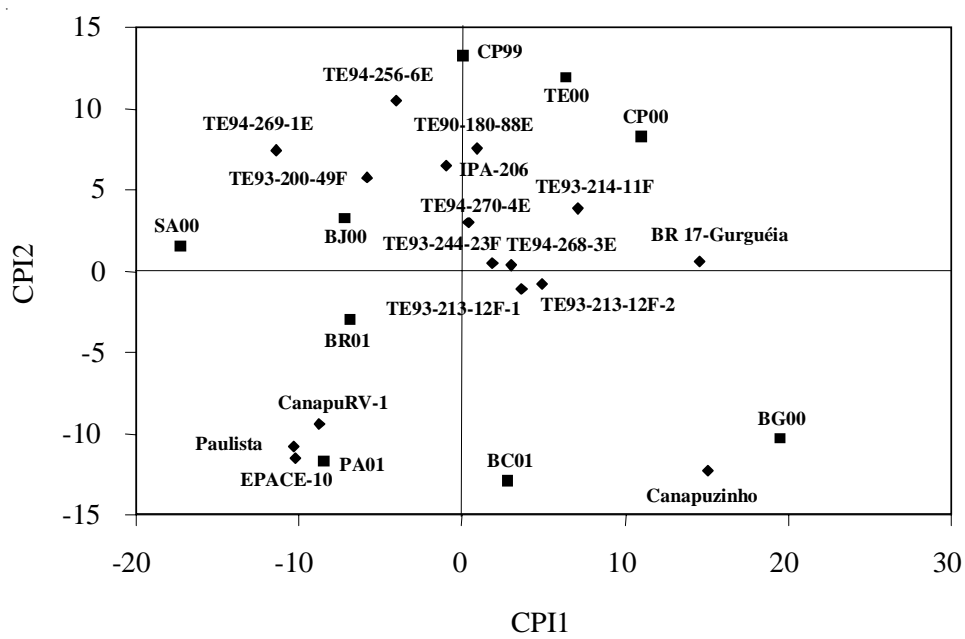

Figura 2. Biplot AMMI2 ou modelo de efeitos aditivos principais e interação multiplicativa, considerando os dois primeiros eixos da análise de componentes principais: primeiro componente principal da interação (CPI1) x segundo componente principal da interação (CPI2), de 16 genótipos ( $\bullet$ ) de feijão caupi, avaliados em nove ambientes ( $)$ do Meio-Norte do Brasil (BC01: Barra do Corda, MA, 2001; BG00: Baixa Grande do Ribeiro, PI, 2000; BJ00: Bom Jesus, PI, 2000; BR01: Brejo, MA, 2001; CP99: Castelo do Piauí, PI, 1999; CP00: Castelo do Piauí, PI, 2000; PA01: Palmeira do Piauí, PI, 2001; SA00: Sambaíba, MA, 2000; TE00: Teresina, PI, 2000).

\section{Conclusões}

1. Os genótipos TE93-244-23F e TE93-213-12F-1 reúnem genes que conferem adaptabilidade e estabilidade e podem ser cultivados em todos os ambientes estudados.

2. Os genótipos Canapuzinho, BR 17-Gurguéia e EPACE-10 expressam melhor seu potencial produtivo em ambientes de alta qualidade.

3. Os ambientes Baixa Grande do Ribeiro, PI, 2000, Bom Jesus, PI, 2000, Sambaíba, MA, 2000 e Palmeira do Piauí, PI, 2001 apresentam boa adaptabilidade, porém apenas os dois primeiros são previsíveis.

4. A interação genótipos x ambientes é variável dentro e homogênea entre os estados do Piauí e Maranhão em termos de qualidade ambiental.

\section{Referências}

ACCIARESI, H. A.; CHIDICHIMO, H. O. Interacción genotipo-ambiente en Avena sativa L. utilizando los modelos AMMI y factorial de correspondencias. Pesquisa Agropecuária Brasileira, Brasília, v. 34, n. 10, p. 18231830, out. 1999.

ANNICCHIARICO, P. Joint regression vs AMMI analysis of genotype-environment interactions for cereals in Italy. Euphytica, Dordrecht, v. 94, n. 1, p. 53-62, 1997.

BORGES, L. C.; FERREIRA, D. F.; ABREU, A. F. B.; RAMALHO, M. A. P. Emprego de metodologias de avaliação da estabilidade fenotípica na cultura do feijoeiro (Phaseolus vulgaris L.). Revista Ceres, Viçosa, MG, v. 47, n. 269, p. 89-102, 2000.

CROSSA, J. Statistical analysis of multilocal trials. Advances in Agronomy, San Diego, v. 44, p. 55-85, 1990. 
CRUZ, C. D.; REGAZZI, A. J. Modelos biométricos aplicados ao melhoramento genético. Viçosa, MG: UFV, 1994. 390 p.

DUARTE, J. B.; VENCOVSKY, R. Interação genótipos $\mathbf{x}$ ambientes: uma introdução à análise "AMMI". Ribeirão Preto: Sociedade Brasileira de Genética, 1999. 63 p. (Série Monografias, 9).

EBERHART, S. A.; RUSSEL, W. A. Stability parameters for comparing varieties. Crop Science, Madison, v. 6 , p. 36-40, 1966.

FERNANDES, J. B.; HOLANDA, J. S.; SIMPLÍCIO, A. A.; BEZERRA NETO, F.; TORRES, J.; REGO NETO, J. Comportamento ambiental e estabilidade produtiva de cultivares de caupi no Rio Grande do Norte. Pesquisa Agropecuária Brasileira, Brasília, v. 25, n. 11, p. 15551560, nov. 1990

FERNANDES, J. B.; HOLANDA, J. S.; SOUZA, N. A.; CHAGAS, M. C. M. Adaptabilidade ambiental e incidência de viroses em cultivares de caupi no Rio Grande do Norte. Pesquisa Agropecuária Brasileira, Brasília, v. 28, n. 1, p. 33-37, jan. 1993.

FINLAY, K. W.; WILKINSON, G. N. The analysis of adaptation in plant breeding programme. Australian Journal of Agricultural Research, Collingwood, v. 14, p. 742-754, 1963.

FOX, P. N.; CROSSA, J.; ROMAGOSA, I. Multienvironmental testing and genotype $\mathrm{x}$ environment interaction. In: KENPTON, R. A.; FOX, P. N. (Ed.). Statistical methods for plant variety evaluation. London: Chapman \& Hall, 1997. p. 117-138.

FREIRE FILHO, F. R.; RIBEIRO, V. Q.; ROCHA, M. M.; LOPES, A. C. A. Adaptabilidade e estabilidade da produtividade de grãos de linhagens de caupi de porte enramador. Revista Ceres, Viçosa, MG, v. 49, n. 234, p. 383-393, 2002.

FREIRE FILHO, F. R.; RIBEIRO, V. Q.; ROCHA, M. M.; LOPES, A. C. A. Adaptabilidade e estabilidade de rendimento de grãos de genótipos de caupi de porte semi-ereto. Revista Científica Rural, Bagé, v. 6, n. 2, p. 31-39, 2001.

GAUCH, H. G. Statistical analysis of regional yield trials: AMMI analysis of factorial designs. New York: Elsevier Science, 1992. 278 p.

GAUCH, H. G.; ZOBEL, R. W. AMMI analysis of yield trials. In: KANG, M. S.; GAUCH, H. G. (Ed.). Genotypeby-environment interaction. New York: CRC Press, 1996. $416 \mathrm{p}$.

GOLLOB, H. F. A statistical model which combines features of factor analytic and analysis of variance techniques. Psychometrika, Baltimore, v. 33, n. 1, p. $73-115,1968$

Pesq. agropec. bras., Brasília, v. 38, n. 5, p. 591-598, maio 2003
MIRANDA, P.; COSTA, A. F.; OLIVEIRA, L. R.; TAVARES, J. A.; PIMENTEL, M. L.; LINS, G. M. L. Comportamento de cultivares de Vigna unguiculata (L.) Walp., nos sistemas solteiro e consorciado - I: tipo ramador. Ciência Agronômica, Fortaleza, v. 23, n. 1/2, p. 9-19, 1992.

MIRANDA, P.; COSTA, A. F.; OLIVEIRA, L. R.; TAVARES, J. A.; PIMENTEL, M. L.; LINS, G. M. L. Comportamento de cultivares de Vigna unguiculata (L.) Walp., nos sistemas solteiro e consorciado - III: tipo ramador. Pesquisa Agropecuária Pernambucana Recife, v. 10, p. 67-76, 1997. Número especial.

NACHIT, M. M.; NACHIT, G.; KETATA, H.; GAUCH, H. G.; ZOBEL, R. W. Use of AMMI and linear regression models to analyze genotype-environment interaction in durum wheat. Theoretical and Applied Genetics, Berlin, v. 83 , n. 5 , p. 597-601, 1992.

PEREIRA, A. S.; COSTA, D. M. Análise de estabilidade de produção de genótipos de batata no Rio Grande do Sul. Pesquisa Agropecuária Brasileira, Brasília, v. 33, n. 4, p. 405-409, abr. 1998

PIEPHO, H. P. Robustness of statistical test for multiplicative terms in the additive main effects and multiplicative interaction model for cultivar trial. Theoretical and Applied Genetics, Berlin, v. 90, n. 3/4, p. 438-443, 1995.

ROCHA, M. M. Seleção de linhagens experimentais de soja para adaptabilidade e estabilidade fenotípica. 2002. 174 f. Tese (Doutorado em Genética e Melhoramento de Plantas) - Escola Superior de Agricultura Luiz de Queiroz, Piracicaba, 2002.

SANTOS, C. A. F.; ARAÚJO, F. P.; MENEZES, E. A. Comportamento produtivo de caupi em regimes irrigado e de sequeiro em Petrolina e Juazeiro. Pesquisa Agropecuária Brasileira, Brasília, v. 35, n. 11, p. 2229 2234, nov. 2000

SAS INSTITUTE (Cary, Estados Unidos). SAS/STAT software: changes and enhancements through release 6.12 . Cary, 1997. $1116 \mathrm{p}$.

YAU, S. K. Regression and AMMI analyses of genotype $\mathrm{x}$ environment interactions: an empirical comparison. Agronomy Journal, Madison, v. 87, n. 1, p. 121-126, 1995.

ZOBEL, R. W.; WRIGHT, M. J.; GAUCH, H. G. Statistical analysis of a yield trial. Agronomy Journal, Madison, v. 80, n. 3, p. 388-393, 1988. 